\title{
Dementia with Leukoencephalopathy in Systemic Lupus Erythematosus
}

\author{
Andrew Kirk, Andrew Kertesz and Marsha J.Polk
}

\begin{abstract}
Neurologic manifestations, afflicting up to 70\% of SLE patients, include psychosis, seizures, chorea, neuropathies, and stroke. MRI is useful in evaluation of lupus patients and several reports have documented cerebral atrophy or focal hyperintensities. We report an unusual MRI appearance in a 56-year-old woman with SLE, diagnosed on the basis of pleuritis, lymphopenia, anti-DNA antibodies, and neurologic involvement. She reported recent onset of Raynaud's phenomenon and generalized macular rash. She presented after two months of gradual deterioration with memory loss, flattened affect, dysphagia, dysarthria, anomia, and somnolence, without focal neurologic signs. Investigations included elevated ESR, reduced complement, normal CSF without oligoclonal bands, negative viral serology, normal hormone and vitamin levels, normal renal and hepatic function. Neuropsychologic testing showed widespread impairment (WAIS-R: FSIQ-63; WMS-69; DRS-98; RCPM14; WAB AQ-78.8). CT was normal but MRI showed strikingly symmetric, confluent hyperintensities extensively involving cerebral and cerebellar white matter on $\mathrm{T} 1$ and $\mathrm{T} 2$ weighted scans. Basal ganglia and subependymal and subcortical white matter were spared. Treated with prednisone, the patient made a gradual, but incomplete, recovery. These MRI findings may reflect widespread vasculopathy or direct immunologic brain insult with or without imunologic blood-brain barrier disruption.

RÉSUMÉ: Démence avec leuco-encéphalopathie dans le lupus érythémateux aigu disséminé. Les manifestations neurologiques qui touchent plus de $70 \%$ des patients atteints de lupus érythémateux aigu disséminé (LEAD) incluent la psychose, les convulsions, la chorée, les neuropathies et l'ictus cérébral. L'imagerie par résonnance magnétique (IRM) est utile dans l'évaluation des patients souffrant de lupus et plusieurs communications ont documenté une atrophie cérébrale ou des foyers hyperintenses. Nous rapportons le cas d'une femme âgée de 56 ans atteinte de LEAD, dont le diagnostic avait été posé sur la base d'une pleurite, d'une lymphopénie, de la présence d'anticorps anti-ADN et d'une atteinte neurologique, et chez qui l'imagerie par résonnance magnétique présentait un aspect inusité. Elle rapportait le début récent d'un phénomène de Raynaud et une irruption maculaire généralisée. Elle a consulté suite à une période de détérioration de deux mois, avec une altération de la mémoire, une athymie, une dysphagie, une dysarthrie, une anosmie et de la somnolence, sans signe neurologique focal. L'investigation a montré une élévation de la vitesse de sédimentation, un taux sérique du complément abaissé, un LCR normal sans bande oligoclonale, une sérologie virale négative, des niveaux d'hormones et de vitamines normaux, une fonction rénale et hépatique normale. Les épreuves neuropsychologiques ont montré une atteinte étendue (WAIS-R : FSIQ-63; WMS-69; DRS-98; RCPM-14, WAB AQ-78.8). La tomodensitométrie était normale, mais l'IRM a montré des zones confluentes d'hyperintensité, remarquablement symétriques, impliquent la substance blanche cérébrale et cérébelleuse à l'imagerie pondérée par T1 et T2. Les ganglions de la base et la substance blanche sous-épendymaire et sous-corticale étaient épargnés. La patiente a récupéré graduellement mais incomplètement sous prednisone. Ces constatations à l'IRM peuvent refléter une vasculopathie étendue ou une atteinte immunologique directe du cerveau avec ou sans perturbation de la barrière hémoencéphalique.
\end{abstract}

Can. J. Neurol. Sci. 1991; 18: 344-348

Second only to renal disease as a cause of death in SLE, 1 neurologic complications are clinically manifest in $50-70 \%$ of SLE patients. ${ }^{2-4}$ Occasionally the initial disease manifestation, neurologic SLE may first present in the final weeks of life in up to a third of patients. ${ }^{2}$

Like systemic features, neurologic manifestations of SLE are protean and the nervous system can be affected at any level. ${ }^{2}$ Study of neurologic SLE has been hampered by the lack of a generally accepted clinical or pathophysiologic classification.
Tentative classification systems ${ }^{5}$ generally attempt to distinguish first between primary CNS lupus and the more common 6 secondary CNS manifestations ascribed to systemic disease, infection, or therapy.

Cognitive impairment is the most common neurologic finding in SLE, occurring in up to $66 \%$ of patients, including almost half of patients without overt neurologic symptomatology. ${ }^{7}$ Denburg et al. ${ }^{8}$ documented impairment on a wide variety of neuropsychologic tests, rather than a specific pattern of cognitive

From the Department of Clinical Neurological Sciences, Lawson Research Institute, St. Joseph's Health Centre, University of Western Ontario, London Received November 13, 1990. Accepted January 10, 1991

Presented in part at the XXVth Canadian Congress of Neurological Sciences, Banff, Alberta, June 1990

Reprint requests to: Andrew Kirk, Department of Medicine (Neurology), Royal University Hospital, Saskatoon, Saskatchewan, Canada S7N 0X0 
involvement in SLE. In another neuropsychologic study, Sonies et al. ${ }^{9}$ concluded that SLE patients, especially those with psychiatric involvement, suffered from reduced ability to focus and maintain attention in order to complete tasks.

Aside from infections and systemic disorders such as uremia and hypertension, several mechanisms have been suggested to explain cognitive impairment in SLE. Neuropsychologic deficits may result from cerebral infarcts secondary to cardiogenic emboli. ${ }^{4}$ Infarcts may be related to the presence of antiphospholipid antibodies ${ }^{10}$ and multi-infarct dementia has been described in association with these antibodies.11,12 Much less commonly, deficits may be attributable to immune complex-mediated vasculitis. ${ }^{2,13}$ A noninflammatory small vessel vasculopathy may also occur. ${ }^{2,13}$ Autoantibodies reactive with neuronal cell membranes or cytoskeleton have been identified in the serum and CSF of up to $75 \%$ of SLE patients and may be of higher titer in those with neurologic manifestations. ${ }^{14-19}$ Thus, direct immunologic injury to neurons has been proposed as a potential mechanism for neurologic SLE. Some have suggested that, in addition to antineuronal antibodies, an alteration in the blood-brain barrier is also required ${ }^{3.20}$ Fields and colleagues ${ }^{21}$ found anticardiolipin antibodies in the serum but not the CSF of SLE patients with "infarct-like" lesions on MRI. Although anticardiolipin antibody has been linked with cerebral infarction and migraine, ${ }^{10,22}$ it seems less likely that it plays a direct role in diffuse cerebral dysfunction. ${ }^{21}$

Cognitive impairment is SLE thus appears to reflect heterogeneous patterns of deficits which may result from several distinct pathological processes. There is some evidence ${ }^{23}$ that patients with brain cross-reactive lymphocytotoxic antibodies tend to share a particular pattern of impairment (mainly visuospatial) despite the overall neuropsychologic variability found in SLE patients.

CT scanning has identified atrophy, hematomas, and infarcts in SLE. ${ }^{24-28}$ MRI has proven more sensitive. ${ }^{29-32}$ Several investigations have documented atrophy, infarcts, and hematomas on MRI. 19,29-34 These same studies have also revealed lesions not typically seen on CT. These include focal hyperintensities in white matter, in gray matter, and at the corticomedullary junction and vary from large single lesions to multiple tiny abnormalities. McCune et al. ${ }^{31}$ found that focal lesions were much more common in patients with focal signs than in those with nonspecific cognitive decline. Sewell et al. ${ }^{35}$ maintained that the yield from MRI is small unless a focal lesion is suggested clinically. The relationship between these focal abnormalities often seen on MRI and cognitive impairment, the commonest neurologic manifestation of SLE, is still unclear.

\section{Case Report}

Two months prior to presentation at St. Joseph's Health Centre in August, 1987, S.N., a previously healthy 56-year-old high-school-educated homemaker, developed a generalized erythematous macular rash which resolved completely after several days. At about the same time, she developed typical Raynaud's phenomenon (which persisted) and intermittent diarrhea. Over the next two months, there was steady neurological decline. She became forgetful, leaving faucets running and burners on. She became somnolent and uninterested in her surroundings. Affect was blunted. She no longer initiated conversation and was slow to respond to questions. According to her family, S.N. was normally outgoing and gregarious, with many social contacts and a ready wit. Her voice became quiet, slurred, and halting. Dysphagia developed with occasional choking, particularly on liquids. She had frequent hiccups.
There was no history of fever, chills, or sweats. She had no previous history of skin rashes or neurologic complaints. She had never suffered from photosensitivity, dry eyes or mouth, alopecia, arthralgias, or mucosal ulcers. S.N. had been taking no medications and had no allergies. Apart from an episode of jaundice in her 20's she had been free of illness. There was no family history of rheumatologic or neurologic disease.

On examination, S.N., although awake, was confused and extremely withdrawn, with flat affect. Vital signs and general examination were normal. She was disoriented to time and place. Speech was hypophonic, dysarthric, and hesitant. There were occasional phonemic paraphasias. Naming and repetition were impaired. After a long delay, she followed most simple commands. Instances of verbal and motor perseveration were observed. She could repeat only three digits forward and was unable to do serial 7's or 3's. She remembered none of three objects after one minute. Writing was poorly formed and illegible. She read only simple sentences. Her drawings were simplified scrawls. There was no evidence of hemispatial neglect. She could tell left from right. Thinking was concrete. Praxis was normal. Cranial nerves and fundi were normal. Motor examination was normal apart from mild gegenhalten, more marked on the right. Sensory examination was normal, as were deep tendon reflexes. Plantar responses were flexor. Palmomental reflexes were present bilaterally. Glabellar tap produced sustained blinking. There was no grasp response. Gait was slow and shuffling but she could perform tandem gain adequately. Her vocal cords were seen to move normally on indirect laryngoscopy.

Within a week of admission, S.N. developed chest pain and was found to have bilateral pleural effusions not seen on a radiograph done nine days previously. Thoracentesis revealed these to be exudative. No organisms were grown from the fluid.

Investigations carried out on S.N. are summarized in Table 1. Neuropsychologic testing revealed marked global cognitive dysfunction (Table 2). Serum and CSF viral serology and cultures were negative, as was HIV titer. Vitamin $B_{12}$, folate, plasma $A C T H$, liver enzymes, urea, creatinine, urinalysis, blood sugar, thyroid function, PT, PTT, and 2-D echocardiogram were all normal. Electroencephalogram showed $9 \mathrm{~Hz}$ alpha rhythm with normal reactivity and intermittent bursts of theta and delta in both frontotemporal regions. An isotope brain scan was normal. CT scan was also completely normal. HMPAO-SPECT scanning

Table 1: Laboratory Investigations

\begin{tabular}{lll}
\hline \hline Hemoglobin & $12.2 \mathrm{~g} / \mathrm{L}$ & \\
White cell count & $12.8 \times 10^{9} / \mathrm{L}$ & \\
& $\left(1.0 \times 10^{9} / \mathrm{L}\right.$ lymphocytes) & (lymphopenic) \\
Platelets & 147 & \\
Erythocyte sed. rate & 85 & \\
VDRL & negative & (norm. 80-160 \\
$\mathrm{CH}_{50}$ & $20 \mathrm{u}$ & (norm. 0.83-1.77) \\
$\mathrm{C}_{3}$ & $0.61 \mathrm{~g} / \mathrm{L}$ & (norm. 0.15-0.45) \\
$\mathrm{C}_{4}$ & $0.09 \mathrm{~g} / \mathrm{L}$ & (norm. 0-21) \\
$\mathrm{C}_{1 \mathrm{q}}$ binding & $91 \mathrm{u}$ & (norm $<60)$ \\
Rheumatoid factor & $1940 \mathrm{ku} / \mathrm{l}$ & \\
Anti-ENA & negative & \\
Anti-Sm & negative & \\
Anti-RNP & negative & \\
Anti-La & negative & \\
Anti-Ro/SS-A & negative & \\
ANA & negative & (norm. $<25)$ \\
Anti-DNA & $50 \mathrm{u} / \mathrm{h}$ & \\
Anticardiolipin & positive & \\
CSF chemistry & normal & \\
CSF cytology & no cells & \\
Oligoclonal banding & negative & \\
Serum protein & polyclonal increase in gamma \\
electrophoresis & &
\end{tabular}

(Abbreviations: VDRL - Venereal Disease Research Laboratory test. $\mathrm{CH}_{50}$ - Total hemolytic complement. C - Complement. ENA Extractable Nuclear Antigen. RNP - Ribonucleoprotein. ANA Antinuclear antibody. DNA - Deoxyribonucleic acid. CSF Cerebrospinal fluid.) 
showed diminished flow bilaterally in the frontal lobes. Acute MRI scans (Figure 1), demonstrated extensive, confluent hyperintensity of the cerebral and cerebellar white matter which was bilateral and symmetric. Shortly after admission, S.N. was started on prednisone $80 \mathrm{mg}$ daily. Over the next three weeks in hospital, there was a marked improvement in her spontaneity, affect, grooming, and cognition. Prednisone was gradually tapered to zero over the next ten months. Within two months she was again able to cook, shop, and do her usual housework. Her speech and swallowing had improved greatly. Within a year of her initial presentation, she had reached a plateau. Since that time, she has been left with mild hypophonia and some trouble with her memory. Her family feels that her affect and spontaneity are back to normal. She is able to carry out her household duties as before. Her neuropsychologic improvement is documented in Table 2. Follow-up MRI scans up to 29 months after presentation showed progressive cerebral atrophy and shrinkage of the abnormal areas of white matter (Figure 2).

\section{Discussion}

- This woman's illness, characterized by four of the American Rheumatism Association's major diagnostic criteria ${ }^{36}$ (pleuritis, lymphopenia, neurologic disorder, and anti-DNA antibodies) and
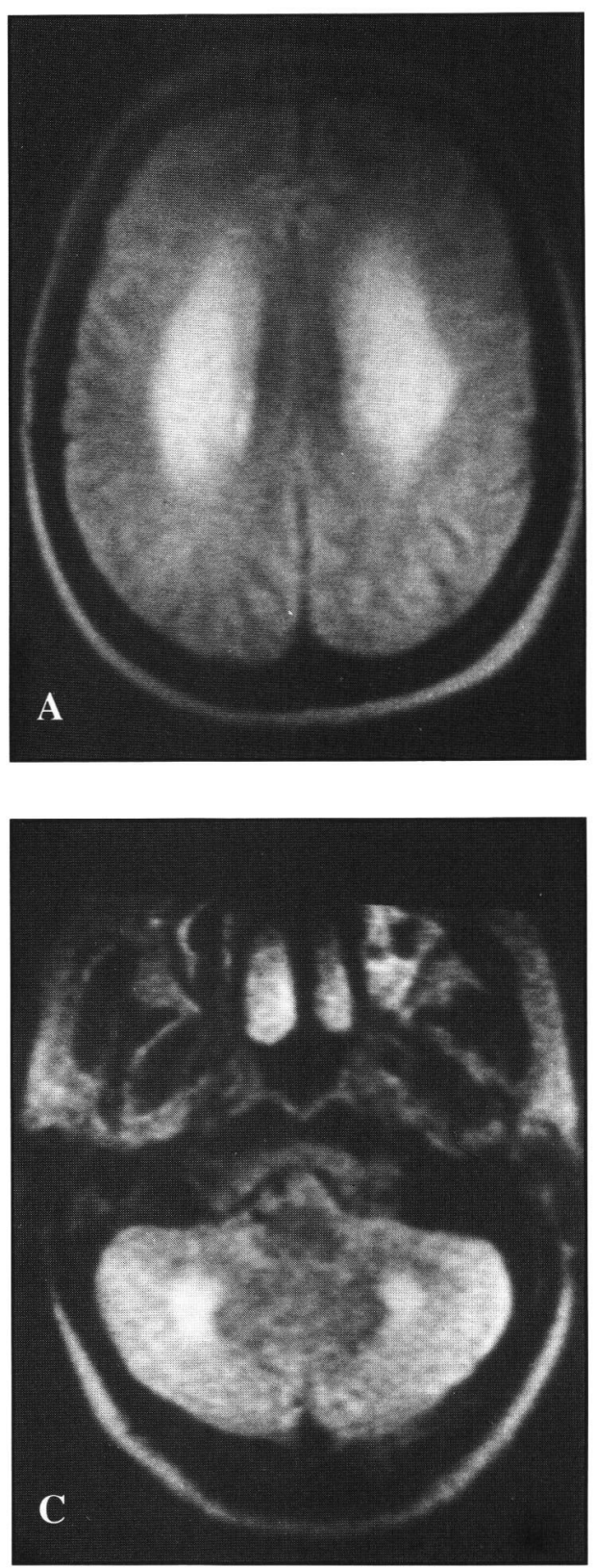
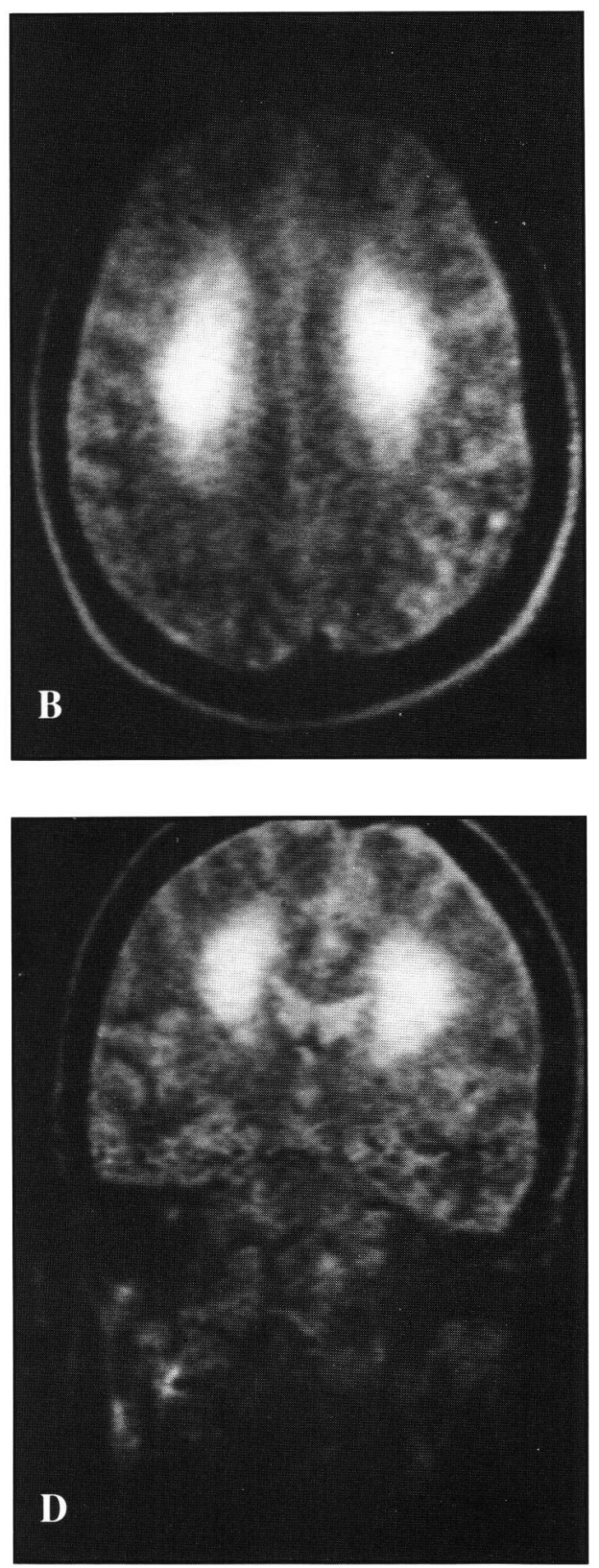

Figure I - Magnetic resonance images of S.N. in August, 1987, two months after the onset of her illness. A) Axial TI image, demonstrating extensive. bilateral hyperintensity of cerebral white matter. This image was obtained using a time to repetition (TR) of $2400 \mathrm{~ms}$ and a time to echo (TE) of $60 \mathrm{~ms}$. B) Axial T2-weighted spin echo image showing hyperintensity of cerebral white matter. TR $2400 \mathrm{~ms}$, TE I20 ms. C) Axial Tl image demonstrating hyperintensity bilaterally in cerebellar white matter. TR $2400 \mathrm{~ms}$, TE $60 \mathrm{~ms}$. D) Cornonal T2 image showing essentially symmetric hyperintensity of cerebral white matter: TR $2400 \mathrm{~ms}, T E 120 \mathrm{~ms}$. 
Table 2: Neuropsychological testing

\begin{tabular}{lcccc}
\hline \hline & $\mathbf{1 3 / 8 / 8 7}$ & $\mathbf{2 4 / 8 / 8 7}$ & $\mathbf{8 / 8 8}$ & $\mathbf{1 / 9 0}$ \\
\hline Western Aphasia Battery & & & & \\
Information content /10 & 8 & 8 & 8 & 9 \\
Fluency /10 & 5 & 5 & 5 & 9 \\
Comprehension /10 & 9.6 & 9.2 & 10 & 9.6 \\
Repetition /10 & 9.2 & 9 & 9.6 & 9.6 \\
Naming /10 & 7.6 & 8 & 8.1 & 8.6 \\
Reading /100 & - & - & 73 & 84 \\
Praxis /60 & - & - & 58 & 54 \\
Calculation /24 & - & - & 22 & 24 \\
Aphasia Quotient & 78.8 & 78.4 & 81.4 & 91.6 \\
Wechsler Memory Scale & & & & \\
Memory Quotient & 69 & 67 & 92 & - \\
Wechsler Memory Scale - Revised & & & & \\
Verbal Memory Index & - & - & 71 & 60 \\
Visual Memory Index & - & - & 74 & 63 \\
General Memory Index & - & - & 74 & 63 \\
Mattis Dementia Rating Scale & & & & \\
Total Score /144 & 98 & 105 & 115 & 116 \\
Wechsler Adult Intelligence & & & & \\
$\quad$ Scale-Revised & & & & \\
Verbal IQ & & - & 73 & 70 \\
Performance IQ & 67 & - & 76 & 72 \\
Full-Scale IQ & 63 & & & \\
\hline & 63 & & & \\
\end{tabular}

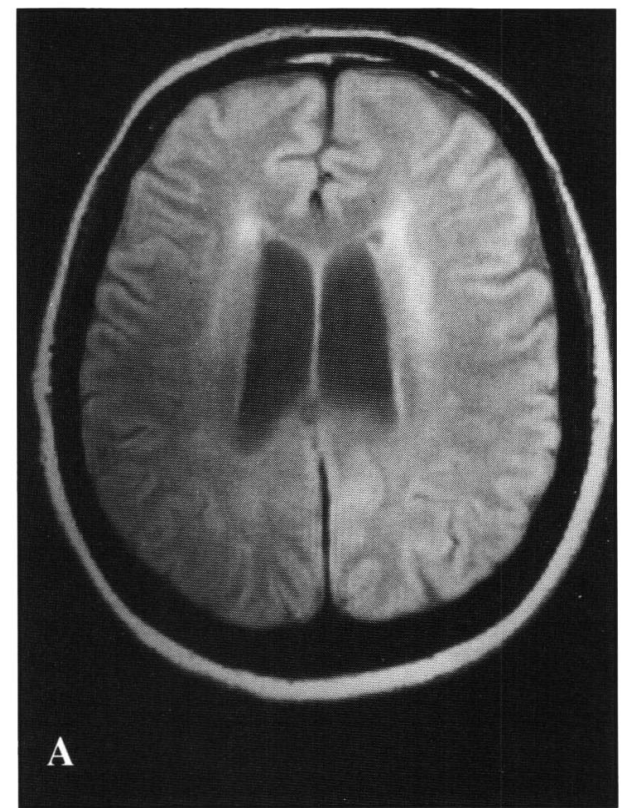

by skin rash, Raynaud's phenomenon, hypocomplementemia, anticardiolipin antibodies, evidence of circulating immune complexes, and mild thrombocytopenia, is consistent with SLE. Her neurologic condition with generalized cognitive decline and social withdrawal approaching catatonia resembles previous reports of neurologic SLE which, unfortunately, of ten do not present results of neuropsychologic tests or clearly distinguish between psychosis and dementia which are frequently grouped together as neuropsychiatric lupus or "organic brain syndrome" 5,37-39

The pathogenesis of this patient's cognitive impairment is not certain. Given the unique finding of extensive and confluent white matter changes on MRI, the absence of focal signs, and the steady progression of her illness, it seems unlikely that her signs could be explained by multiple infarcts due to cardiac emboli, large vessel arteritis, or a thrombotic diathesis. Degenerative and proliferative changes affecting small vessels extremely diffusely throughout the brain ${ }^{2}$ might be implicated, as might direct immunologic damage to brain with or without disturbance of the blood-brain barrier.

The striking abnormalities on MRI contrast dramatically with the normal findings on CT, bearing out the greater sensitivity of MRI in neurologic SLE. ${ }^{29-32}$ Contrary to reports that MRI is abnormal mainly in those with focal signs ${ }^{31,35}$, this case shows that MRI can also be useful in investigating patients with nonfocal neurologic disease in SLE.

Although S.N. was left with some cognitive impairment, her substantial recovery and lack of new symptoms over three years of follow-up illustrate the point that devastating neurologic symptoms early in the disease are not necessarily harbingers of an aggressive or lethal course.

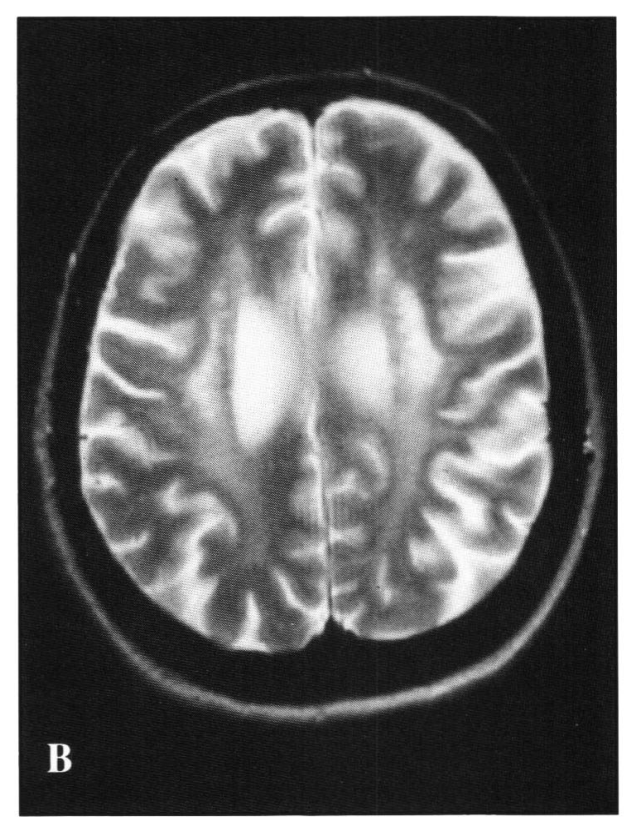

Figure 2 - Magnetic resonance images of S.N. in January, 1990, thirty-one months after the onset of her illness. A) Axial Tl image showing ventricular enlargement, cerebral atrophy, shrinkage of the previously affected cerebral white matter with low signal areas anteriorly within the abnormal regions. TR $2500 \mathrm{~ms}$, TE $22 \mathrm{~ms}$. B) Axial T2 image demonstrating ventricular enlargement, cerebral atrophy, shrinkage of previously affected cerebral white matter. TR $2500 \mathrm{~ms}$, TE $90 \mathrm{~ms}$. 


\section{ACKNOWLEDGEMENTS}

Andrew Kirk was supported by a Fellowship from the Canadian Heart and Stroke Foundation. This study was also supported by PSI Foundation grant No. 88-15 to Andrew Kertesz.

\section{REFERENCES}

1. Dubois EL, Tuffanelli DL. Clinical manifestations of SLE: computer analysis of 520 cases. JAMA 1964; 190: 104-111.

2. Johnson RT, Richardson EP. The neurological manifestations of systemic lupus erythematosus: a clinical-pathological study of 24 cases and review of the literature. Medicine 1968; 47: 337-369.

3. McCune WJ, Golbus J. Neuropsychiatric lupus. Rheum Dis Clin North Am 1988; 14: 149-167.

4. Devinsky O, Petito CK, Alonso DR. Clinical and neuropathological findings in systemic lupus erythematosus: the role of vasculitis, heart emboli, and thrombotic thrombocytopenic purpura. Ann Neurol 1988; 23: 380-384.

5. Bresnihan B. CNS lupus. Clin Rheum Dis 1982; 8: 183-195.

6. Kaell AT, Shetty M, Lee BCP, et al. The diversity of neurologic events in systemic lupus erythematosus: prospective clinical and computed tomographic classification of 82 events in 71 patients. Arch Neurol 1986; 43: 273-276.

7. Carbotte RM, Denburg SD, Denburg JA. Prevalence of cognitive impairment in systemic lupus erythematosus. J Nerv Ment Dis 1986; 174: 357-364.

8. Denburg SD, Carbotte RM, Denburg JA. Cognitive impairment in systemic lupus erythematosus: a neuropsychological study of individual and group deficits. J Clin Exp Neuropsychol 1987; 9: 323-339.

9. Sonies, BC, Klippel JH, Gerber RB, et al. Cognitive performance in systemic lupus erythematosus. Arthritis Rheum 1982; 25 (suppl): $\mathbf{5 8 0 .}$

10. Levine SR, Welch KMA. The spectrum of neurologic disease associated with antiphospholipid antibodies. Lupus anticoagulant and anticardiolipin antibodies. Arch Neurol 1987; 44: 876-883.

11. Asherson RA, Khamashta MA, Gil A, et al. Cerebrovascular disease and antiphospholipid antibodies in systemic lupus erythematosus, lupus-like disease, and the primary antiphospholipid syndrome. Am J. Med 1989; 86: 391-399.

12. Asherson RA, Mercey D, Phillips G, et al. Recurrent stroke and multi-infarct dementia in systemic lupus erythematosus: association with antiphospholipid antibodies. Ann Rheum Dis 1987; 48: 605-611.

13. Ellis SG, Verity MA. Central nervous system involvement in systemic lupus erythematosus: a review of neuropathologic findings in 56 cases, 1955-1977. Semin Arthritis Rheum 1979; 8: 212-221.

14. Bluestein HG, Zvaifler NJ. Brain-reactive lymphocytotoxic antibodies in the serum of patients with systemic lupus erythematosus. J Clin Invest 1976; 57: 509-516.

15. Bresnihan B, Oliver M, Grigor R, et al. Brain-reactivity of lymphocytotoxic antibodies in SLE with and without cerebral involvement. Clin Exp Immunol 1977; 30: 333-337.

16. Bluestein HG, Williams GW, Steinberg AD. Cerebrospinal fluid antibodies to neuronal cells; association with neuropsychiatric manifestations of systemic lupus erythematosus. Am J Med 1981; 70: 240-246.

17. How A, Dent PB, Liao S-K, et al. Antineuronal antibodies in neuropsychiatric lupus. Arthritis Rheum 1985; 28: 789-795.

18. Denburg JA, Carbotte RM, Denburg SD. Neuronal antibodies and cognitive function in systemic lupus erythematosus. Neurology 1987; 37: 464-467.

19. Robbins ML, Kornguth SE, Bell CL, et al. Antineurofilament antibody evaluation in neuropsychiatric systemic lupus erythemato- sus: combination with anticardiolipin antibody assay and magnetic resonance imaging. Arthritis Rheum 1988; 31: 623-631.

20. Bluestein HG, Zvaifler NJ. Antibodies reactive with central nervous system antigens. Hum Pathol 1983; 14: 424-428.

21. Fields RA, Sibbitt WL, Toubbeh, et al. Neuropsychiatric lupus erythematosus, cerebral infarctions, and anticardiolipin antibodies. Ann Rheum Dis 1990; 49: 114-117.

22. Hogan MJ, Brunet DG, Ford PM, et al. Lupus anticoagulant, antiphospholipid antibodies and migraine. Can J Neurol Sci 1988; 15: 420-425.

23. Denburg SD, Carbotte RM, Long AA, et al. Neuropsychological correlates of serum lymphocytotoxic antibodies in systemic lupus erythematosus. Brain Behav Immunol 1988; 2: 222-234.

24. Carette S, Urowitz MB, Grosman $\mathrm{H}$, et al. Cranial computerized tomography in systemic lupus erythematosus. J Rheumatol 1982; 9: 855-859.

25. Bilaniuk LT, Patel S, Zimmerman RA. Central nervous system disease in systemic lupus erythematosus. Radiology 1977; 124: 119-121.

26. Gonzalez-Scarano F, Lisak RP, Bilaniuk LT, et al. Cranial computed tomography in the diagnosis of systemic lupus erythematosus. Ann Neurol 1979; 5: 158-165.

27. Killian PJ, Schnapf DJ, Lawless OG. Computerized axial tomography of central nervous system lupus. Arthritis Rheum 1979; 22: 628-629.

28. Gaylis N, Altman, RD, Ostrov S, et al. The selective value of computer assisted tomography (CAT) of the brain in cerebritis due to systemic lupus erythematosus (SLE). Arthritis Rheum 1981; 24: s120.

29. Vermess M, Bernstein RM, Bydder GM, et al. Nuclear magnetic resonance (NMR) imaging of the brain in systemic lupus erythematosus. J Comput Assist Tomogr 1983; 7: 461-467.

30. Aisen AM, Gabrielsen TO, McCune WJ. MR imaging of systemic lupus erythematosus involving the brain. Am J Neuroradiol 1985; 144: 1027-1031.

31. McCune WJ, MacGuire A, et al. Identification of brain lesions in neuropsychiatric system lupus erythematosus by magnetic resonance scanning. Arthritis Rheum 1988; 31: 159-166.

32. Sibbitt WL, Sibbitt RR, Griffey RH, et al. Magnetic resonance and computed tomographic imaging in the evolution of acute neuropsychiatric disease in systemic lupus erythematosus. Ann Rheum Dis 1989; 48: 1014-1022.

33. Jacobs L, Kinkel PR, Costello PB, et al. Central nervous system lupus erythematosus: the value of magnetic resonance imaging. $J$ Rheumatol 1988; 15: 601-606.

34. Suzuki K, Hara M, Nakajima S, et al. Analysis of systemic lupus erythematosus (SLE) involving the central nervous system by magnetic resonance imaging. Ryumachi 1989; 29: 88-96.

35. Sewell KL, Livneh A, Aranow CB, et al. Magnetic resonance imaging versus computed tomographic scanning in neuropsychiatric systemic lupus erythematosus. Am J Med 1989; 86: 625. 626.

36. Tan EM, Cohen AS, Fries JF, et al. The 1982 revised criteria for the classification of SLE. Arthritis Rheum 1982; 25: 1271-1277.

37. Lief VF, Silverman T. Psychosis associated with lupus erythematosus disseminatus. Arch Gen Psychiatr 1960; 3: 608.

38. Feinglass EJ, Arnett FC, Dorsch CA, et al. Neuropsychiatric manifestations of systemic lupus erythematosus: diagnosis, clinical spectrum and relationship to other features of the disease. Medicine 1976; 55: 323-339.

39. Stern M, Robbins ES. Psychosis in systemic lupus erythematosus. Arch Gen Psych 1960; 3: 205-212. 